\title{
Mobilizações na rede social: o partido espanhol Podemos e o cenário eleitoral brasileiro
}

\author{
Carla Montuori Fernandes' Eva Campos Domínguez²
}

\section{Resumo}

O artigo tem por objetivo mapear e analisar as mensagens veiculadas sobre o cenário político brasileiro no Twitter do Partido Podemos, com o intuito de desvelar a narrativa adotada pelo partido espanhol, durante o período que se estende ao decreto de prisão do ex-presidente Luiz Inácio Lula da Silva (PT), em 05 de abril até 28 de outubro de 2018, data do final do segundo turno das eleições presidenciais. Já é recorrente as manifestações do partido Podemos no Twitter sobre o conturbado cenário político brasileiro, com criticas freqüentes ao processo de impeachment que culminou com a chegada do Presidente Michel Temer (MDB) ao poder. Após a expedição do mandato de prisão do ex-presidente Lula (PT) pela Justiça Federal as inferências contrárias se intensificaram. O marco teórico que tenciona a pesquisa é o potencial que as redes sociais abarcam no sentido de ampliar o diálogo político e consolidar uma rede de apoio político-partidário para além da esfera nacional. A pesquisa buscará refletir sobre a capacidade de mobilização dos novos agentes políticos que nasceram das redes e da comunicação digital. Será utilizada a análise de conteúdo como metodologia (BARDIN, 2011).

\section{Palavras-chave}

Comunicação; Política; Eleições; Redes Sociais; Brasil-Espanha. 


\section{Mobilizations in the social network:}

\section{the spanish party Podemos and the brazilian electoral scenario}

\section{Carla Montuori Fernandes ${ }^{1}$ Eva Campos Domínguez²}

\section{Abstract}

The article aims to map and analyze the messages conveyed about the Brazilian political scenario on the Podemos party's twitter, in order to unveil the narrative adopted by the Spanish party, during the period extending to the former president's arrest decree Luiz Inácio Lula da Silva (PT), from April 5 to October 28, 2018, the date of the end of the second round of presidential elections. The party's demonstrations are already recurring Podemos party on Twitter about the troubled Brazilian political scene, with frequent criticism of the impeachment process that culminated with the arrival of President Michel Temer (MDB) to power. After the issuance of the arrest warrant of former President Lula (PT) by the Federal Court, the contrary inferences intensified. The theoretical framework that the research intends is the potential that social networks embrace to broaden political dialogue and consolidate a party-political support network beyond the national sphere. The research will seek to reflect on the mobilization capacity of the new political agents born from networks and digital communication. Content analysis will be used as a methodology (BARDIN, 2011).

\section{Keywords}

Communication; Politics; Elections; Social Networks; Brazil-Spain 
No Brasil, a vitória presidencial do ex-presidente Luiz Inácio Lula da Silva (PT) em 2002 marca o início de programas de transferência de renda, como o Bolsa Família, entre outros de cunho social, responsáveis por transformar a luta social e a desigualdade em um problema de gestão de políticas públicas. Com dois mandatos presidenciais consecutivos (2002-2006 e 2006-2010), Lula articula a campanha eleitoral vitoriosa de sua sucessora Dilma Rousseff (PT) nas eleições presidenciais de 2010 e 2014.

Nas eleições presidenciais de 2014, o ciclo de encerramento dos 12 anos da Era Lula dava sinais de enfraquecimento. Singer e Loureiro (2016) identificam que as ondas de protestos em massa que se iniciaram em junho 2013, a reeleição apertada que garantiu a vitória de Dilma em 2014, a desintegração da base governista no Congresso Nacional, além da adoção de uma política de ajuste fiscal que protegia as elites econômicas em 2015 representavam sinais da debilidade do governo petista.

Em março de 2014 foi o início da midiatização da Operação Lava Jato [1] em que foram cumpridos diversos mandados de busca e apreensão, de prisões e conduções coercitivas. Devido às personalidades políticas que investigava, rapidamente a Lava Jato ganhou grande relevância e alcance da população. O auge se deu no dia 24 de outubro de 2014, véspera da votação do segundo turno da disputa presidencial, quando a edição da Revista Veja veiculou em sua capa a imagem do ex-presidente Lula e, à época, da presidente e candidata à reeleição Dilma, com a acusação de saber sobre o esquema de corrupção na Petrobras [2].

O doleiro Alberto Yousseff, preso em uma das fases da Operação Lava Jato, disse, em sua delação, que Lula e Dilma sabiam do esquema do da Lava Jato [3]. A partir de então, nota-se vazamentos seletivos do processo ganhando capas de jornais e revistas pelo país. Na sequência ocorreram mais acusações e vazamentos, agora não só sobre o Partido dos Trabalhadores (PT), mas colocando o sistema partidário brasileiro sob suspeita.

Entre os inúmeros desdobramentos desta operação, o ex-presidente Lula tornou-se alvo de denúncias e réu em algumas ações. Em 12 de julho de 2017, Lula foi condenado a nove anos e seis meses de reclusão por corrupção e lavagem de dinheiro no caso do tríplex de Guarujá, condenação esta em que foi interposto recurso à instância superior.

No cenário conturbado da política brasileira, as mídias sociais ocuparam um espaço importante na organização das manifestações, nos processos contra os 
governantes e na criminalização dos atores políticos. Como exemplo, as mobilizações nas redes sociais favoráveis e contrárias ao ex-presidente Lula se propagaram para além do cenário nacional ganhando repercussão entre os agentes e instituições internacionais. Possível candidato na corrida eleitoral para presidente do país em 2018, o decreto de prisão de Lula, em 5 de abril, ressignificou o debate eleitoral e suscitou ações efetivas dos atores e partidos políticos.

É sobre esse ponto que a investigação tem início. Após o mandato de prisão de Lula, nota-se uma série de manifestações pelas redes sociais de diversos partidos políticos e intelectuais consagrados, em âmbito nacional e internacional. O partido espanhol Podemos propagou a campanha Lula Livre, com coberturas sobre os desdobramentos que ganharam enorme visibilidade na mídia nacional. O partido tem manifestado indignação constante frente aos desdobramentos jurídicos que culminaram com a prisão de Lula.

O Podemos é um partido de esquerda que surgiu em 2014, como desdobramento do movimento espanhol 15-M, também conhecido como Movimentos dos Indignados, em um contexto de crise econômica e política e precárias condições de vida na Espanha. Na esteira do Movimento dos Indignados emerge o Podemos que herdará o discurso, as estratégias de luta e a combatividade da sociedade civil. O movimento se institucionalizou tendo como ponto de destaque a alegação que o sistema político e os partidos tradicionais espanhóis mostravam-se ineficientes e incapazes de atender as demandas da sociedade civil em ebulição (MARTIN, 2015; SOUSA SANTOS, 2015).

Diante da projeção e importância que o Podemos conquistou no contexto global, optamos por mapear e analisar todas as manifestações do partido espanhol e dos seus integrantes [4], Pablo Iglesias (Fundador do Partido) e Pablo Bustinduy (Porta-voz de Assuntos Exteriores), desde a prisão de Lula, em 5 de abril de 2018, até o fim das eleições presidenciais brasileiras, em 28 de outubro do mesmo ano, com o intuito de responder qual o discurso que prevaleceu no Twitter do partido. De modo mais efetivo, será testada a hipótese de que o Podemos se engajou na campanha eleitoral brasileira em total apoio ao Partido dos Trabalhadores (PT), manifestado pelas redes sociais.

Para análise dos dados publicados no Tzitter do Podemos optaremos pela abordagem quantitativa. Para coleta de dados optou-se pela utilização da plataforma Flocker que permite armazenar em um banco de dados todos os posts publicados na rede. A análise e interpretação dos resultados serão baseadas nas tabelas construídas na etapa quantitativa, em consonância com o marco teórico da análise de conteúdo de Bardin (2011). 
Para analisar o cenário que conduziu a eleição presidencial de 2018 será necessário retomar a conjuntura em que se instaurou uma forte mobilização social e política, que amparadas pelas mídias digitais, repercutiram para além da esfera nacional. As mobilizações sociais de junho de 2013 acirram um ambiente de polarização política que caminhou por uma narrativa em que Lula e o Partido dos Trabalhadores ocuparam o cerne do debate (NOBRE, 2013; SOUZA, 2016; GOHN, 2017).

Idealizadas pelo grupo intitulado Movimento Passe Livre (MPL), a motivação tinha o intuito de levar a sociedade às ruas para protestar contra o aumento dos preços cobrados nos transportes públicos. Com destaque inicialmente em São Paulo, mas ganhando força com o passar dos acontecimentos em várias outras cidades e capitais; o foco das manifestações deixou de ser governos municipais e passou a ser o governo federal (GOHN, 2017).

Na ocasião, a então presidente Dilma declarou, em rede nacional, reconhecer a legitimidade das manifestações e anunciou que seria elaborado um projeto direcionado à melhoria dos serviços públicos. Contudo, nos anos seguintes, foi crescente o número de protestos nas ruas e novos assuntos foram incluídos na pauta dos manifestantes, entre eles: críticas à Copa das Confederações, à queda do consumo e ao aumento na taxa de desemprego, além de críticas à corrupção - esta última ligada aos escândalos de corrupção iniciados em 2005 com o Mensalão [4] e ganhando um novo capítulo com as investigações da Operação Lava Jato. Para o pesquisador Jessé Souza (2016), o Mensalão, a Lava Jato e as manifestações aqui citadas, que ficaram conhecidas como "Jornadas de Junho" tiveram o mesmo objetivo: desacreditar o governo e construir uma base popular para o golpe.

O cenário conturbado de pós-eleição presidencial de 2014 que reconduziu Dilma (PT) à presidência e o posterior processo de impeachment da presidente foi interpretado por alguns de autores (SINGER, 2015; SALUM Jr., 2016; SINGER e LOUREIRO, 2016; SANTOS, 2017) como os esforços das elites dominantes para consolidação de uma política neoliberal conservadora, que ansiava pelo fim da era petista.

O vice-presidente Michel Temer (MDB) assumiu o governo com forte oposição de movimentos sociais e de partidos de esquerda que o acusaram de golpe por ter rompido com as regras do jogo democrático. Autores como Souza (2016) e Santos (2017) analisam o impeachment como uma articulação de forças do Legislativo e do Judiciário, com amplo apoio da imprensa hegemônica e setores da elite e de boa parte 
da classe média descontente com o governo Dilma.

Diante desse cenário político conturbado, em 12 de julho de 2017, Lula foi sentenciado a cumprir pena pela condenação de nove anos e seis meses por corrupção e lavagem de dinheiro no caso do tríplex do Guarujá. Com forte repercussão nacional e internacional, a prisão de Lula mobilizou setores da esquerda e da sociedade civil organizada, que se apoiaram no discurso da arbitrariedade da condenação e na tentativa de excluir Lula da corrida presidencial de 2018. Mesmo preso, Lula entrou na corrida presidencial, quando o Partido dos Trabalhadores oficializou sua candidatura em 15 de agosto de 2018. Entretanto, em 31 de agosto de 2018, o Tribunal Superior Eleitoral (TSE) rejeitou candidatura do ex-presidente petista.

O descumprimento da decisão liminar do Comitê de Direitos Humanos da Organização das Nações Unidas (ONU), que indicou a necessidade do Estado brasileiro garantir as medidas necessárias para que Lula exercesse seus direitos políticos mesmo na prisão, como candidato nas eleições presidenciais de 2018, incluindo acesso apropriado à mídia e a integrantes de seu partido político, gerou repercussão negativa em diversas instâncias e organizações internacionais.

Na linha de reprovação das medidas judiciais envolvendo o ex-presidente Lula, o partido espanhol Podemos lançou inúmeros manifestos nas redes sociais, comentando e questionando as decisões. Com tradição na utilização das mídias digitais e consolidado como partido político no início de 2014, o Podemos tornouse a quarta bancada mais votada na Espanha nas eleições de maio do mesmo ano. Apesar de certo abrandamento no discurso, Silva (2016) elucida que o Podemos pode ser considerado o único partido de esquerda consolidado na Europa. Desde sua constituição, o Podemos busca certa aproximação com os partidos de esquerda ao redor do mundo, apoiando manifestações, sobretudo em momentos de turbulências políticas. Nesse sentido que se pretende investigar qual a narrativa adotada pelo partido Podemos no Tæiitter, envolvendo o cenário político e eleitoral brasileiro.

\section{Twitter como ferramenta política de mobilização social}

Destacadamente, o uso das tecnologias digitais em períodos eleitorais ganhou centralidade nas pesquisas acadêmicas e mercadológicas, desde a campanha vitoriosa do ex-presidente americano Barack Obama, em 2008. Lemos e Levy (2010) elencam que as transformações mais significativas da comunicação ocasionada pelo advento da comunicação digital estão relacionadas às mudanças na organização e na cultura, que acabam por alterar os modos pelos quais as relações de poder operam no século 
XXI. Trata-se de um novo espaço de sociabilidade, com novas formas de interações sociais, códigos e estruturas próprias. No campo político deve-se pontuar que essa possibilidade de associação ultrapassa os percursos tradicionais de representação da política, já que elimina a intermediação e possibilita formas horizontais e diretas de atuação e transformação (EGLER, 2010).

Diante do papel revolucionador dos meios digitais, sobretudo em função de como as notícias são consumidas e construídas, Newman, Duttone e Blank (2012) cunharam a expressão "quinto poder" para designar um processo que ultrapassa a mídia tradicional. Nesse contexto, as mídias digitais como blogues, Facebook, Tæitter, YouTube e outras ferramentas de redes sociais assumiram nos últimos anos um papel importante na criação de discursos disponibilizados por produtores não especializados para grandes audiências, atuando também como catalisadores de mobilizações sociais.

Entre as inúmeras temáticas abordadas na literatura, para efeito do artigo, tem relevância os estudos sobre o engajamento de políticos e partidos on-line, por analisarem o nível de utilização das tecnologias digitais e a forma como são incorporadas no cotidiano político (VACGARI e NIELSEN, 2013; BRAGA; NICOLÁS e BECHER, 2013 e NICOLÁS e BRAGA, 2015). A discussão sobre redes sociais digitais, especificamente o Twitter, objeto dessa análise, já foi retomada em um número significativo de estudos, que abarcam o uso frequente dos atores políticos, assim como as estratégias de comunicação acionadas durante o cenário eleitoral (RECUERO, 2016; CERVI e MASSUCHIN, 2011).

A esfera pública constituída no Twitter, segundo Recuero (2016), aponta para as relações de poder da ferramenta, que vão desde a influência na propagação de determinadas mensagens em detrimento de outras, até as disputas do espaço offline. Para a autora, "a mídia social, através de sites como o Twitter e o Facebook têm papel importante na ampliação dos espaços de debate público, e a sua influência na construção e no desafio do discurso dominante é muito importante" (RECUERO et. al., 2014, p. 162).

No cenário espanhol, SÁNCHEZ e DAMAS (2015) apontam que o Twitter se configura como um modelo de comunicação para que diversos públicos, entre os quais formadores de opinião e atores políticos, emitam opiniões e propaguem informações, ampliando a qualidade democrática. Considerando, então, que o Twitter tem promovido novos processos comunicativos e ampliado a esfera política, buscamos direcionar uma análise para os perfis do partido espanhol Podemos. 


\section{Abordagem Metodológica}

O texto traz como proposta analisar a atuação do partido espanhol Podemos nas eleições presidenciais brasileiras, com o intuito de focar nas seguintes questões de pesquisa: (1) o Podemos adotou o discurso de aproximação com a esquerda brasileira, considerando o processo de condenação e prisão de Lula um ato seletivo da justiça, visando afastá-lo do cenário eleitoral?; (2) o Podemos manifestou apoio a algum partido ou candidato na disputa presidencial brasileira?

Como metodologia de pesquisa será utilizada a análise de conteúdo, já que se trata de um método com grande aderência aos estudos dos discursos on-line. Diante das diversas formas e abordagens, Bardin (2011) aponta que a análise de conteúdo permite o estudo do espaço digital a partir da abordagem quantitativa e qualitativa.

Aanálise de conteúdo(BARDIN, 2011) se baseia em três etapas, sendo, codificação de dados, categorização e inferências. Na primeira etapa, denominada codificação, foram selecionadas as menções ao ex-presidente Lula e as eleições presidenciais do Brasil em 2018, nas contas do Twitter do partido Podemos e de seus integrantes, Pablo Iglesias - Secretário Geral do Partido, e Pablo Bustinduy - porta-voz de Exteriores, do período de 5 de abril até 28 de outubro de 2018. O levantamento de dados possibilita maior clareza sobre como se articulou o discurso político do tema nas redes. Nesse sentido, foram monitoradas as atividades de contas dos usuários @ahorapodemos, @Pablo_Iglesias_e @pbustinduy, durante o período já indicado. Vale ressaltar que o Partido Podemos divide sua agenda entre os temas nacionais, europeus e latinoamericanos, o que reduz em quantidade o número de tweets sobre o Brasil.

A análise está dividida em duas partes. Na primeira, foi realizada uma abordagem quantitativa de todos os tweets e retweets com menções a Lula e às eleições presidenciais no Brasil. A quantidade e o número de retweets de um comentário também foram contabilizados nas tabelas abaixo. Os temas tratados nos tweets foram elencados em categorias para subsidiar a segunda e terceira etapas da análise, que apoiarão na descrição e interpretação do conteúdo postado.

Na segunda etapa da análise quantitativa, foi utilizado o procedimento de mineração de dados, por meio das ferramentas de análise de texto, com o intuito de produzir nuvem de palavras, matriz termo-documento e classificação hierárquica dos termos. 


\begin{tabular}{|l|l|}
\hline Nome & Podemos \\
\hline Nome do usuário & @ahorapodemos \\
\hline Bibliografia & $\begin{array}{l}\text { Un país feminista y donde nadie se quede } \\
\text { fuera. La España que nacióel 15M. Construimos } \\
\text { contigo una mayoría para recuperar La } \\
\text { dignidad y los derechos }\end{array}$ \\
\hline Número de seguidores & 1,34 \\
\hline Número de pessoas que seguem & 1526 \\
\hline & $\begin{array}{l}\text { Lula Livre } \\
\text { Lula candidato } \\
\text { Decisão da ONU } \\
\text { Alvará de soltura de Lula } \\
\text { Lula fora da disputa eleitoral }\end{array}$ \\
\hline Temas & 6 \\
\hline Quantidade de Tweet sobre a prisão de Lula & 3 \\
\hline Quantidade de Tweet sobre eleições presidenciais & $\begin{array}{l}\text { \#LulaLivre } \\
\text { \#EleNão } \\
\text { \#MoroNãoEstáAcimadaLei }\end{array}$ \\
\hline Hashtags &
\end{tabular}

Tabela 1: Uso do Twitter pelo Podemos - menções a Lula e eleições presidenciais no Brasil. Fonte: Elaborado pelas autoras (2019)

Como se pode observar na Tabela 1, o tweet foi a função mais utilizada pelo Podemos durante o período analisado, sendo que o partido publicou seis menções sobre Lula e três sobre as eleições presidenciais do Brasil. O partido retuitou apenas uma reportagem publicada por Pablo Bustinduy sobre a prisão de Lula. No aspecto temático, as menções ao processo de prisão de Lula e seus desdobramentos na justiça ocupam seis publicações, ou seja, 66,66\% do espaço dedicado ao tema. As principais hashtags acionadas foram LulaLivre, principal tema da campanha para libertação de Lula e EleNão, frase usada por opositores da candidatura de Bolsonaro. Ambas estiveram presentes em três tweets.

\begin{tabular}{|l|l|}
\hline Nome & Pablo Iglesias \\
\hline Nome do usuário & @Pablo_Iglesias_ \\
\hline Bibliografia & $\begin{array}{l}\text { Padre. Secretario Gral. de @ahorapodemos y } \\
\text { diputado em El Congreso. Profesor honorífico } \\
\text { de la UCM. Nadie duda de que este país ya ha } \\
\text { cambiado. ¡Sí se puede! }\end{array}$ \\
\hline Número de seguidores & 2,24 mil \\
\hline Número de pessoas que seguem & 2724 \\
\hline Temas & Lula Livre \\
\hline Quantidade de Tweet sobre a prisão de Lula & 3 \\
\hline Quantidade de Tweet- eleições presidenciais & 2 \\
\hline
\end{tabular}




\begin{tabular}{|l|l|}
\hline Retweet & - \\
\hline Hashgtag & \#Caixa2doBolsonaro \\
\hline
\end{tabular}

Tabela 2: Uso do Twitter por Pablo Iglesias - menções a Lula e eleições presidenciais no Brasil. Fonte: Elaborado pelas autoras. (2019)

Ao tratar do tema Lula e Eleições, o secretário geral do Podemos, Pablo Iglesias (Tabela 2), publicou três tweets sobre a prisão de Lula e o impedimento de sua candidatura, e dois sobre as eleições presidenciais brasileiras, destacando uma clara oposição ao candidato Bolsonaro. No aspecto temático, as menções ao processo de prisão de Lula e seus desdobramentos ocupam três publicações, ou seja, 6o \% do espaço dedicado ao tema. A hashtag Caixa 2 de Bolsonaro acompanhou o tweet com a denúncia do jornal Folha de S. Paulo sobre um suposto uso indevido das redes sociais na campanha do candidato pesselista.

\begin{tabular}{|l|l|}
\hline Nome & Pablo Bustinduy \\
\hline Nome do usuário & @pbustinduy \\
\hline Bibliografia & $\begin{array}{l}\text { Porta voz de Exteriores y diputado } \\
\text { de @ahorapodemos por Madrid. } \\
\text { CoordinolaSecretaría Internacional @ } \\
\text { PodemosInter). Las ideas se miden en sus } \\
\text { efectos. }\end{array}$ \\
\hline Número de seguidores & 38,4 mil \\
\hline Número de pessoas que seguem & 1522 \\
\hline & $\begin{array}{l}\text { Lula Livre } \\
\text { Lula candidato } \\
\text { Decisão da ONU } \\
\text { Lula fora da disputa eleitoral } \\
\text { Golpe no Brasil }\end{array}$ \\
\hline Temas & 2 \\
\hline Quantidade de Tweets sobre a prisão de Lula & 3 \\
\hline Quantidade de Tweets - eleições presidenciais & \#LulaLivre \\
\hline Hashtag &
\end{tabular}

Tabela 3: Uso do Twitter por Pablo Bustinduy - menções a Lula e eleições presidenciais no Brasil.

Fonte: Elaborado pelas autoras. (2019)

O tweet foi a função mais utilizada por Pablo Bustinduy (Tabela 3), durante o período analisado, com duas menções sobre a prisão de Lula e três sobre as eleições presidenciais brasileiras. O porta voz de exteriores do Partido Podemos compartilhou três tweets com links para manifestar apoio à candidatura de Lula. No aspecto temático, as menções ao processo de prisão de Lula e seus desdobramentos ocupam todas as publicações do porta voz de exteriores do partido espanhol. A hashtag LulaLivre 
aparece apenas em uma das publicações.

\section{Análise dos resultados}

A partir da frequência de palavras nos tweets selecionados, foram produzidas nuvens com 200 palavras, salientando as palavras mais ditas das três contas analisadas, conforme Figura 1.

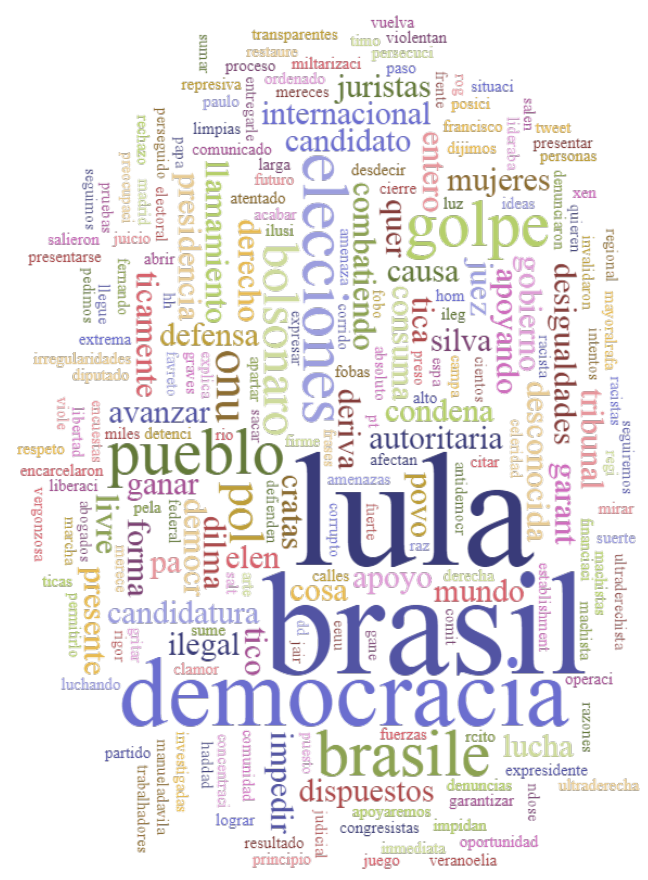

Figura 1: Nuvem de palavras

Fonte:Contas do twitter@ahorapodemos,@Pablo_Iglesias_,@pbustinduy

Pode observar maior freqüência da palavra Lula, seguido pelos termos democracia e Brasil. Nota-se que os tweets das contas analisadas mantêm um posicionamento contrário a prisão de Lula, ou seja, entendem que se trata de uma prerrogativa ilegítima para impedi-lo de participar do processo eleitoral, algo que o partido e seus integrantes consideram um risco à democracia brasileira. Também podemos localizar palavras relacionadas ao impeachment de Dilma Rousseff, como golpe, ilegal e ilegítimo. Na sequência para obter os dados sobre as palavras mais utilizadas foi construída uma matriz termo-documento (Figura 2), exibida em formato de gráfico. 


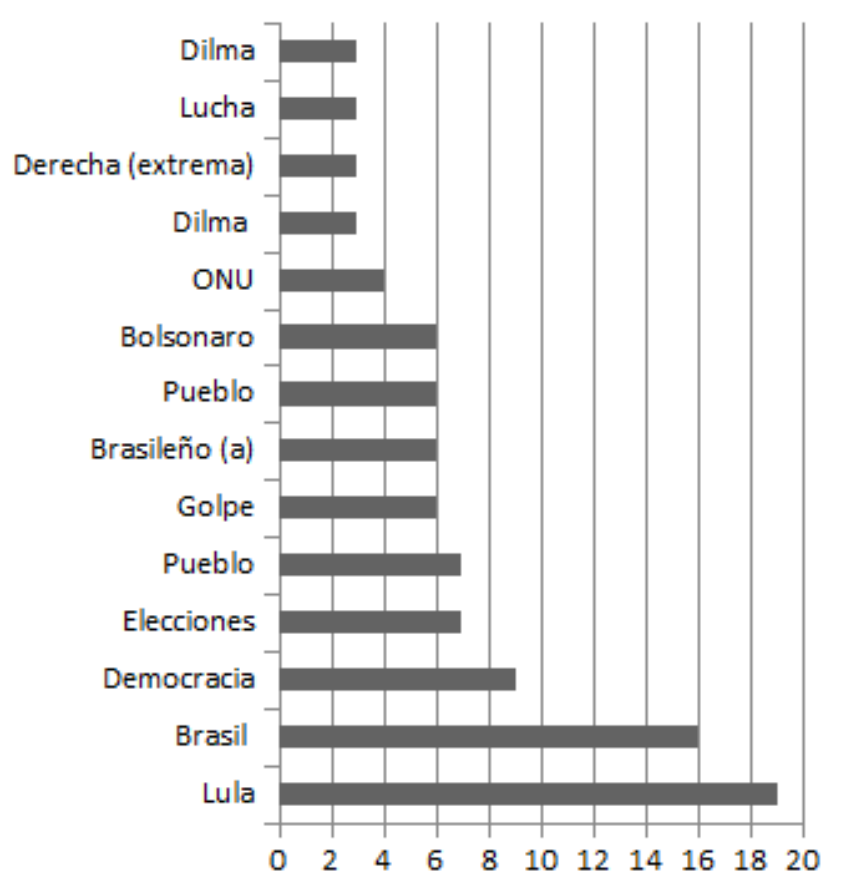

Gráfico 2: Gráfico de palavras mais freqüentes (mínimo 3 menções) Fonte: Contas do twitter@ahorapodemos,@Pablo_Iglesias_,@pbustinduy

Como já foi mencionado, é possível verificar que as palavras Lula, Brasil e Democracia estão entre as mais acionadas pelo Podemos e seus principais integrantes. Não obstante, os termos elecciones, Brasileño (a), golpe, pueblo e Bolsonaro possuem entre 6 e 7 menções, incorporando tweets críticos sobre a conjuntura eleitoral brasileira, acenando para que se realize a vontade do povo, liberte Lula e impeça que Bolsonaro, referenciado como candidato de derecha (extrema) vença o pleito.

Para definição das categorias, aplicamos o processo de codificação conceitual (RECUERO et. al., 2014), e por meio do processo de correlação, buscamos associar termos que se referissem ao mesmo evento. Sendo assim, os termos referentes à prisão e candidatura de Lula se enquadraram na mesma categoria. Já a categoria eleições presidenciais no Brasil abarcou o engajamento em torno da candidatura do Partido dos Trabalhadores e a oposição a campanha de Jair Bolsonaro (PSL).

\section{Lula (PT): prisão e candidatura}

A categoria Lula (PT): prisão e candidatura se dividiram em duas temáticas principais, a saber: a prisão de Lula e a tentativa da justiça brasileira em impedir a candidatura do ex-presidente petista. A campanha pela liberdade de Lula ocupou maior espaço dos tweets do Podemos. Mencionado como preso político, as três contas apontaram que a prisão de Lula representava um atentado contra a democracia, cujo objetivo principal era evitar que o ex-presidente retornasse ao poder. 
O Podemos defende a tese de que Lula é perseguido por Sergio Moro, que desconsidera todas as garantias legais de liberdade do ex-presidente. Um dia após o mandato de prisão de Lula, em 6 de abril, o Podemos publicou um tweet, com link para um manifesto hospedado no site do partido, em que expressa uma absoluta rejeição aos que consideram uma condenação política e à tentativa ilegítima de prendê-lo.

Uma das táticas do Podemos foi publicar tweets em que sinaliza o apoio de organizações externas para reforçar o discurso de perseguição política a Lula. Em 18 de agosto, por exemplo, um dia após o Comitê da ONU acolher o pedido de liminar e determinar que o ex-presidente Lula pudesse exercer os direitos políticos da prisão e disputar as eleições presidenciais de 2018, o Podemos tuitou: "Nós sempre dissemos: estamos com o Lula e com o povo brasileiro. Agora a ONU nos dá a razão”.

Na mesma linha do partido, um dos fundadores do Podemos, Pablo Iglesias, buscou tuitar vídeos em que se coloca ao lado dos apoiadores da democracia no Brasil, em campanha por Lula Livre. Em 12 de abril, Pablo Iglesias publicou fotos do evento "O Futuro das lutas democráticas: em defesa da democracia brasileira”, organizado por Boaventura Souza Santos. Nesse sentido, a comunidade internacional une esforços para impedir isso". Em um novo tweet sobre o evento, Pablo Iglesias publica um vídeo em que pontua os avanços que o governo Lula trouxe para o Brasil ao combater as desigualdades sociais.

No dia 13 de maio, Iglesias fez outra publicação baseada em vídeos, para debater a crise que se instaurou no Brasil desde o impeachment da ex-presidente Dilma. O debate com o tema "Para onde vai o Brasill, retratou os avanços que Lula promoveu no âmbito social, para rechaçar a decisão do Supremo Tribunal Federal (STF), que havia rejeitado o pedido de liberdade do ex-presidente petista. O debate também aponta os riscos e as incertezas que a saída de Lula das disputas eleitorais de 2018 poderia trazer ao Brasil. Já Pablo Bustinduy atuou mais próximo do discurso do Podemos. Investiu em tweets que denunciavam a perseguição a Lula com o intuito de tirá-lo da disputa eleitoral.

Ao retomar a análise sobre o contexto político espanhol, a simpatia do Podemos com governos progressistas sul-americanos, sobretudo os que se constituíram deixando para trás épocas de ajuste neoliberal e encontraram espaço para negociações com o poder financeiro, recuperando certo protagonismo para o Estado, pode ser explicado pelo fato que os modelos representam chaves de leitura para uma narrativa de caráter popular, que segundo Schavelzon (2015), já provou a sua eficácia enquanto dispositivo, para impor-se eleitoralmente baseando-se na reivindicação do social frente a bancos e recortes antipopulares. 
Para Schavelzon (2015, p. 16), o Podemos encontra inspiração nos processos latino-americanos e busca fazer exatamenteo que líderes como Lula da Silva ou o exPresidente do Equador Rafael Correa Delgado propõem a seus críticos: "formar um partido e ganhar - pensa parecido quando enfrenta 'eficácia' de frente às eleições, frente à democracia interna e o pluralismo que a própria força política convocou”.

Assim, além de se mobilizar em torno da causa brasileira, o Podemos parece atuar para fortalecer seu capital social nas redes para além do espaço europeu. Tal prerrogativa dialoga com o pensamento de Levy (1998) ao elencar que subjacentes ao uso da técnica, agem e reagem ideias, projetos, utópias e estratégias de poder.

\section{Eleições Presidenciais no Brasil}

A categoria Eleições presidenciais no Brasil se dividiu em duas temáticas principais: menções ao candidato Jair Bolsonaro (PSL) e apoio à candidatura do Partido dos Trabalhadores, na figura do candidato à presidência Fernando Haddad (PT). Vale ressaltar que as críticas à candidatura de Bolsonaro ocupou maior espaço que o apoio à candidatura de Haddad, com cinco postagens dos seis tæeets. Verifica-se, a partir das três contas analisadas, uma forte menção aos riscos democráticos que o candidato Bolsonaro representa para o Brasil. Todos os tweets ligados ao apoio a candidatura de Haddad (PT) mencionam Bolsonaro como um político racista, homofônico e ligado aos movimentos de extrema direta.

Interessante ressaltar, conforme aponta Sader (2009) que a preocupação dos partidos de esquerda em torno da conjuntura política brasileira representa uma espécie de luta pelo ideário social democrata, já que a vitória presidencial de Lula, em 2002, trouxe uma imensa expectativa em torno da esquerda brasileira, em contraste a crise generalizada da esquerda latino-americana e mundial. Naquele momento a esquerda brasileira, segunda aponta o autor parecia mais forte do que nunca, diante da derrocada da URSS, do enfraquecimento dos partidos comunistas, nacionalistas e socialdemocratas.

Assim, na categoria Eleições presidenciais do Brasil, os três tweets do Podemos alertam para o risco do Brasil eleger Bolsonaro, um candidato de direita ou extrema direita. Em 30 de setembro, o partido tuitou sobre a manifestação promovida pelo movimento de mulheres contra Bolsonaro, com imagens de inúmeros manifestantes nas principais capitais do Brasil, ao lado do texto: "Centenas de milhares de mulheres saíram ontem nas ruas do Brasil para gritarem \#EleNão para Jair Bolsonaro muito alto. As mulheres do Brasil não querem um político racista, homofóbico, direitista”.

Um tweet com vídeo de Vera Noelia, jornalista e feminista do Podemos, em 8 de 
outubro, após o resultado do segundo turno apontar Bolsonaro (PSL) como possível vencedor da disputa contra Haddad (PT), explica o cenário eleitoral brasileiro. Segundo a jornalista, Bolsonaro faz parte de um plano contra a democracia no Brasil, que se desenrola desde o impeachment da ex-presidente Dilma Rousseff (PT).

$\mathrm{Na}$ véspera do segundo turno da eleição presidencial, o Podemos divulgou imagens do Deputado Rafa Mayoral, Membro do Conselho Cidadão do Podemos, que participou do movimento de Arte pela Democracia, nas ruas de São Paulo. O tweet demonstra o apoio do partido ao candidato Haddad (PT), além de refutar a candidatura de Bolsonaro, ao apontar que "O povo brasileiro tem o nosso total apoio contra a ameaça da extrema direita de Bolsonaro. \#EleNão"

Já o partido de Pablo Iglesias publicou dois tweets sobre a disputa presidencial no Brasil. O primeiro, em 5 de outubro, um dia antes da votação do primeiro turno, em que oficializa apoio à candidatura dos Partido dos Trabalhadores, com a imagem de Lula, seguida do texto "Podemos com Haddad e Manuela", às 18 horas, na Praça do Cascorro, em Madrid. Em 19 de outubro, Pablo Iglesias publica um tweet com a capa do jornal Folha de S. Paulo, que aponta possíveis irregularidades na campanha de Bolsonaro. No âmbito de promover uma campanha negativa ao oponente do PT na disputa presidencial, o texto aponta as denúncias sobre o financiamento ilegal da candidatura e apela para que as investigações aconteçam com rigor e rapidez, já que o destino da democracia no Brasil está em jogo, com uma possível vitória de Bolsonaro.

Pablo Bustinduy publicou apenas um tweet em que tratou Bolsonaro como fruto de uma longa operação contra a democracia no Brasil. Relembrou que o impeachment que retirou Dilma da presidência do Brasil e a prisão de Lula, após um julgamento sem provas, fazia parte de um golpe, cujo objetivo era inviabilizar a candidatura do ex-presidente Lula.

\section{Considerações Finais}

O partido Podemos emergiu no contexto do bipartidarismo espanhol, no qual o Partido Popular (PP) e o Partido Socialista Operário Espanhol (Psoe) dominaram a cena política nacional. Ao estudar a formação do Podemos, Silva (2016) relata que a proximidade política e biográfica dos futuros dirigentes do partido com governos progressistas da América do Sul, serviu como base para que o partido avançasse em debates para além do contexto espanhol, com discussões, análises e comentários em torno de fatos políticos de ordem global. Desde o impeachment de Dilma Rousseff (PT), o Podemos expressa constantes críticas ao governo de Michel Temer (MDB), que 
eles descrevem como ilegítimo.

Após o mandato de prisão do ex-presidente Lula(PT) as manifestações no Tritter do partido espanhol tornaram-se mais intensas. O mapeamento das publicações do Tziitter durante o período de análise retrata forte engajamento do partido e de seus membros pela liberdade do ex-presidente Lula. As publicações das três contas analisadas já demonstram uma sintonia com o discurso do Partido dos Trabalhadores (PT), que relatam que Lula sofre perseguição política, cujo intuito era impedir que disputasse as eleições presidenciais de 2018 e retornasse ao poder. O discurso do Podemos e seus integrantes se intensificam ao passo que os desdobramentos da prisão de Lula o afastam da disputa eleitoral. A retórica usada pelo Partido se volta para os riscos democráticos para o Brasil, com os desdobramentos da prisão de Lula que o impedem de retornar ao poder.

Como a impugnação da candidatura de Lula, nota-se que o Podemos e seus integrantes apostam no discurso de oposição a candidatura de Jair Bolsonaro (PSL). Ainda que o apoio ao candidato do Partido dos Trabalhadores Fernando Haddad estivesse explícito, as publicações do Twitter buscam deslegitimar a candidatura do maior opositor do PT nas urnas, sob o risco do país ingressar em uma onda ultraconservadora de extrema direita.

\section{Notas}

[1] Investigação da Polícia Federal Brasileira referente a desvio e lavagem de dinheiro, envolvendo a Petrobras, políticos e empresários de empreiteiras tradicionais.

[2] Eles sabiam de tudo. Revista Veja, ed. 2397, ano 47, outubro de 2014.

[3] Youssef diz que Lula e Dilma sabiam do esquema da Lava Jato. Disponível em: <https:// noticias.uol.com.br/politica/ultimas-noticias/2015/08/25/youssef-diz-a-cpi-que-dilmatinha-conhecimento-de-esquema-da-lava-jato.htm>. Acesso em: 10 nov. 2018.

[4] A escolha dos integrantes está vinculada a projeção de Pablo Iglesias, como um dos fundadores do partido e principal representante da sigla, assim como de Pablo Bustinduy por ocupar o papel de assessor para assuntos exteriores.

[5] Nome dado ao esquema que trataria de financiamento ilegal de campanhas eleitorais, com o consequente desvio de verbas, compras de voto e apoio a candidatos.

\section{Referências}

BARDIN, Laurence. Análise de conteúdo. Lisboa: Edições 7o, 2011.

BRAGA, Sérgio; NICOLÁS, Maria Alejandra; BECHER, André Roberto. Clientelismo, internet e voto: Personalismo e transferência de recursos nas campanhas online para vereador nas 
eleições de outubro de 2008 no Brasil. Opinião Pública, Campinas, v. 19, n. 1, p. 168-197, 2013. Disponível em: < http://bit.ly/2NqJl8H>. Acesso em: 7 nov. 2019

O uso das mídias sociais é um bom preditor do sucesso eleitoral dos candidatos? Uma análise das campanhas on-line dos vereadores das capitais das regiões sul, sudeste, e nordeste do Brasil no pleito de outubro de 2012. In: ALDÉ, Alessandra; MARQUES, Francisco Paulo Jamil (Orgs.). Internet e poder local. Salvador: UFBA, 2015.

CERVI, Emerson Urizzi; MASSUCHIN, Michele Goulart. Novas mídias e eleições 2010: o uso do Twitternas campanhas dos candidatos ao governo do Paraná. In: Encontro da Associação Brasileira dos Pesquisadores em Comunicação e Política, n. IV, 2011. Rio de Janeiro. Anais do IV Encontro da Compolítica: Compolítica, p. 20, 2011. Disponível em: <http://bit.ly/2rpGu7H>. Acesso em: 7 nov. 2019

EGLER, Tamara Tania Cohen. Redes tecnossociais e democratização das políticas públicas. Sociologias, Porto Alegre, n. 23, p. 208-236, 2010. Disponível em: <http://bit.ly/2NoM2aR>. Acesso em: 7 nov. 2019

GOHN, Maria da Gloria. Manifestações e protestos no Brasil: correntes e contracorrentes na atualidade. São Paulo: Cortez Editora, 2017.

LEMOS, André; LÉVY, Pierre. O futuro da internet: em direção a uma ciberdemocracia planetária. São Paulo: Paulus. 2010.

MARTÍN, Irene . Podemos y otros modelos de partido-movimiento. Revista Española de Sociología, Madrid, v. 24, p. 107-114, 2015. Disponível em: <http://bit.ly/36J9wzb>. Acesso em: 7 nov. 2019

NEWMAN, Nic; DUTTON, William; GRANT, Blank. Social media and the news: implications for the press and society. In: DUTTON, William; GRANT, Blank. (Eds.). Society and the internet: how networks of information and communication are changing our lives. Oxford: Oxford University Press, 2012.

NOBRE, Marcos. Choque de democracia: razões da revolta. São Paulo: Companhia das Letras, 2013.

PIERRE, Levy. A inteligência coletiva. Sao Paulo: Loyola, 1998.

REGUERO, Raquel; ZAGO, Gabriela; BASTOS, Marco Toledo. O Discurso dos \#ProtestosBR: análise de conteúdo do Twitter. Galaxia, n. 28, p.199-216, 2014. Disponível em: <http://bit. ly/3200STq>. Acesso em: 7 nov. 2019

O Tzitter como esfera pública: como foram descritos os candidatos durante os debates presidenciais do $2^{\circ}$ turno de 2014? RBLA, n. 16, v. 1, p. 157-180, 2016. Disponível em: $<$ http://bit.ly/2NtCWKa>. Acesso em: 7 nov. 2019

SADER, Amir. A Nova Toupeira. Os Caminhos da Esquerda Latino-Americana. São Paulo: Boitempo, 2009.

SGHAVELZON, Salvador. A formação do Podemos: América do Sul, Populismo pós-colonial e Hegemonia flexível. Novos estud. CEBRAP, n.103, 25 p. 33-57, 2015. Disponível em: <http:// bit.ly/33qzXHH>. Acesso em: 7 nov. 2019

SÁNCHEZ, Miguel Moya; DAMAS, Susana Herrera Damas. Hacia una comunicación política avanzada en la Internet 2.o. Observatorio (OBS*) Journal, v.9 , n. 4, p. 113-139, 2015. Disponível em: <http://bit.ly/2PZ6Kj9>. Acesso em: 7 nov. 2019 
SANTOS, Wanderley Guilherme dos. O golpe parlamentar brasileiro de 2016. Rio de Janeiro: Editora FGV, 2017.

SALLUM Jr., Basilio João. Crise política e impeachment. Novos estud. CEBRAP, São Paulo, v. 35, p. 183-203, 2016. Disponível em: <http://bit.ly/36GI6da>. Acesso em: 7 nov. 2019

SILVA, Ana Lúciada. Podemos: um terremoto político que sacode a Espanha. Cadernos do CEAS, Salvador, n. 237, p. 386-401, 2016. Disponível em: <http://bit.ly/2qwSgMS>. Acesso em: 7 nov. 2019

SINGER, André. Cutucando onças com varas curtas: O ensaio desenvolvimentista no primeiro mandato de Dilma Rousseff (2011-2014). Novos estud. CEBRAP, São Paulo, n. 102, p. 43-71, 2015. Disponível em: <http://bit.ly/2CmNHHR>. Acesso em: 7 nov. 2019.

Boitempo, 2016.

; LOUREIRO, Isabel. As contradições do Lulismo: a que ponto chegamos?. São Paulo:

SOUZA, Jessé. A radiografia do golpe: entenda como e por que você foi enganado. Rio de Janeiro: LeYa, 2016.

SOUSA SANTOS, Boaventura de. The Podemos Wave.

VACCARI, Christian; NIELSEN, Rasmus Kleis.Do People "Like" Politicians on Facebook? Not Really. Large-Scale Direct Candidate-to-Voter Online Communication as an Outlier Phenomenon. International fournal of Communication, California, v. 7, p. 2333-2356, 2013. 